\section{Literature Cited}

1) Bockris, J. O'M. and S. Srinivasan: "Fuel Cells, Their Electrochemistry," p. 419, McGraw-Hill (1969).

2) Berl, W. G: Trans. Electrochem. Soc., 83, 253 (1943).

3) Kastening, B. and W. Faul: Ger. Chem. Eng., 1, 183 (1978).

4) Mizuno, S.: Denki Kagaku, 17, 262, 288 (1949).

5) Oloman, C. and A. P. Watkinson: Can. J. Chem. Eng., 53, 268 (1975).

6) Oloman, C. and A. P. Watkinson: Can. J. Chem. Eng., 54, 312
(1976).

7) Oloman, C. and A. P. Watkinson: J. Appl. Electrochem., 9, 117 (1979)

8) Sudoh, M., H. Kitaguchi and K. Koide: J. Chem. Eng. Japan, 18, 364 (1985).

9) Sudoh, M., T. Sasase, T. Yonebayashi and K. Koide: Kagaku Kogaku Ronbunshu, 11, 70 (1985).

10) Sudoh, M., J. Yugami and T. Shirotsuka: J. Chem. Eng. Japan, 17, 152 (1984)

\title{
GASIFICATION OF COAL IN THE THERMAL ARGON PLASMA
}

\author{
TAKUYA HONDA AND ATSUSHI KANZAWA \\ Department of Chemical Engineering, Tokyo Institute of Technology, Tokyo 152 \\ HIROAKI ANEKAWA \\ Mitsubishi Atomic Power Industry, Inc., Tokyo 105
}

Key Words: High Temperature, Coal, Gasification, Plasma, Acetylene

The thermal decomposition of "Taiheiyo" coal was investigated experimentally, using a thermal argon plasma. The thermal plasma was generated by an are discharge, and the temperature was approximately $10,000 \mathrm{~K}$. The plasma and fine particles of coal were introduced into an $8 \mathrm{~mm}$-i.d. tube reactor. The conversion to gasified products increased with increased plasma flow rate, and showed a maximum with the variation of input power.

The conversion of a coal particle was estimated by the energy balance. The main assumptions were that the decomposition rate was limited by heat transfer, and that the coal particle decomposed at a constant temperature. The results of this method are in good agreement with those of the experiments. The temperature profile within the particle was evaluated by numerical calculation.

\section{Introduction}

Thermal decomposition of coal using a plasma have been studied for the production of acetylene, and many papers ${ }^{2-4,8,9,15,17)}$ have appeared in this field. However, these results are not quantitative because they depend on many different experimental conditions, e.g., the experimental apparatus, kind of coal, input power, plasma flow rate, coal particle size, etc. Only qualitative information has been available.

In this paper, the conversion (defined in section 1.3) was quantitatively investigated. Particles of coal were injected into a thermal argon plasma in a tube, were heated by the plasma, decomposed thermally, and evolved gaseous products. Radial profiles of the temperature of a coal particle were estimated by numerical calculation, and the conversion to gaseous products was calculated by the energy balance in place of the usual numerical analysis. The assumptions used in this study were examined by numerical calculation.

Received February 2, 1984. Correspondence concerning this article should be addressed to $\mathrm{T}$. Honda.

\section{Experiments}

\subsection{Experimental apparatus}

The experimental apparatus consists of a plasma generator, a reacting tube, a cooling tube, a coal feeder and a gas chromatograph as shown in Fig. 1. Figure 2 is a sectional diagram of the plasma generator and the reacting tube. The thermal plasma is generated by an arc discharge between a nozzle anode ( $8 \mathrm{~mm}$ i.d. and $40 \mathrm{~mm}$ in length) and a tungsten rod cathode $(6 \mathrm{~mm}$ o.d. and $35 \mathrm{~mm}$ in height $)$. Both electrodes are cooled by water to protect them from thermal damage. The temperature of the arc column depended upon the electric input power and the argon flow rate, and ranged from 7000 to $14,000 \mathrm{~K}$. The reacting and cooling tubes are made of copper and cooled by water. Both tubes are of $8 \mathrm{~mm}$ i.d. The length of the reacting tube is $120 \mathrm{~mm}$, and that of the cooling tube is $300 \mathrm{~mm}$. Coal particles were fed to the reacting tube in an argon carrier gas through a hole located $50 \mathrm{~mm}$ downstream from the tip of the cathode. The coal feeder supplies fine coal particles 


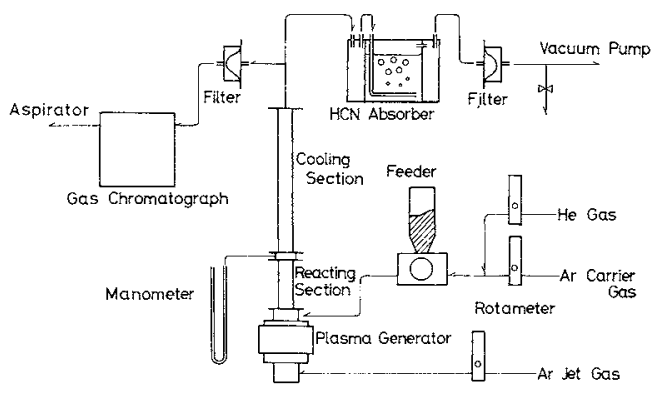

Fig. 1. Experimental apparatus.

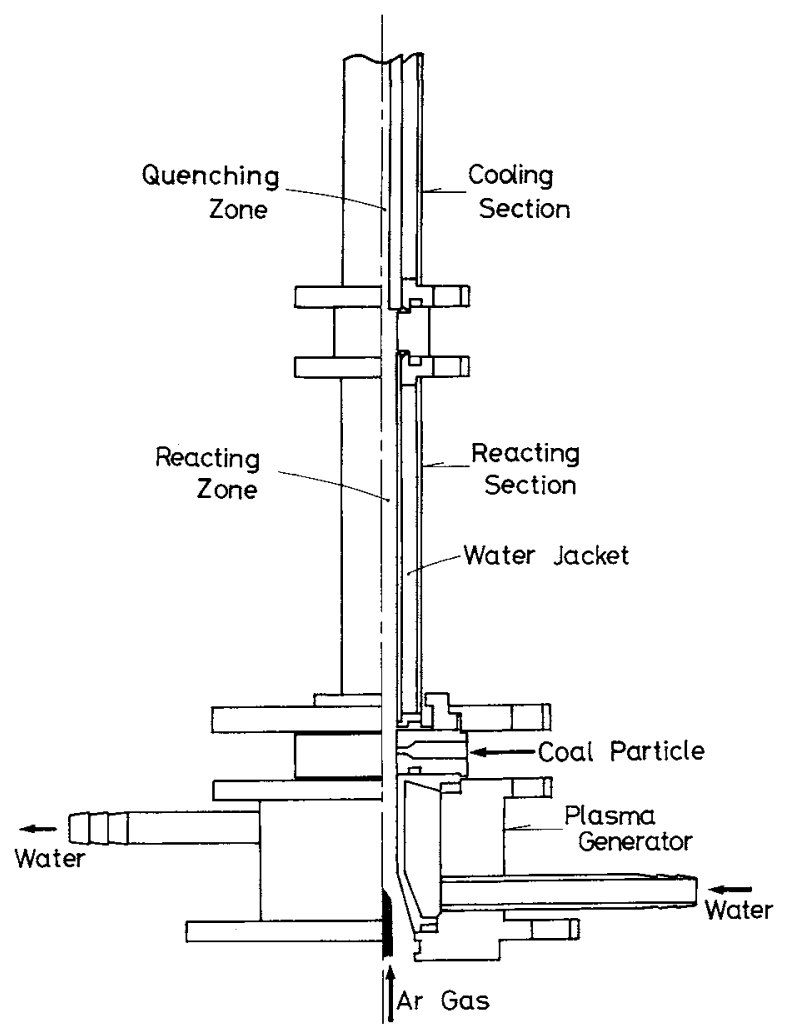

Fig. 2. Sectional diagram of plasma generator and reacting tube.

to the carrier gas flow. The feeder consists of a hopper, a gear, a speed converter, and a motor. The motor drives the gear through the converter, and controls the feed rate of coal by changing the number of revolutions of the gear in the range from 10 to $100 \mathrm{mg} / \mathrm{s}$. The compositions of the product gases were measured by gas chromatograph, using dimethyl formamide and molecular sieve $13 \mathrm{X}$ columns. Helium gas was supplied into the reacting tube in argon carrier gas to measure the conversion.

\subsection{Experimental procedure and conditions}

First, the arc discharge was ignited and the generated thermal plasma was introduced into the reacting tube. After the argon plasma flowed steadily, fine particles of "Taiheiyo" coal were fed into the tube in argon carrier gas at a constant flow rate, $55.4 \mathrm{mg} / \mathrm{s}$. The particles thermally decomposed in the reacting
Table 1. Experimental conditions

\begin{tabular}{lcl}
\hline Argon flow rate & $166-332$ & $\mathrm{mg} / \mathrm{s}$ \\
Electric input power & $1.9-5.2$ & $\mathrm{~kW}$ \\
Coal diameter & $60-100$ & $\mathrm{mesh}$ \\
& or $100-200 \mathrm{mesh}$ \\
Coal feed rate & 47.2 & $\mathrm{mg} / \mathrm{s}$ \\
Pressure in the reaction tube & 101.3 & $\mathrm{~Pa}$ \\
\hline
\end{tabular}

Table 2. Analytical results* for "Taiheiyo" coal

\begin{tabular}{lr}
\hline Proximate analysis: & $5.6 \mathrm{vol} \%$ \\
Water & $9.6 \mathrm{vol} \%$ \\
Ash & $44.8 \mathrm{vol} \%$ \\
Volatile matter & $40.0 \mathrm{vol} \%$ \\
Fixed carbon & \\
Ultimate analysis: & $10.19 \mathrm{wt} \%$ \\
Ash & $69.01 \mathrm{wt} \%$ \\
Carbon & $5.68 \mathrm{wt} \%$ \\
Hydrogen & $1.05 \mathrm{wt} \%$ \\
Nitrogen & $13.53 \mathrm{wt} \%$ \\
Oxygen & $0.24 \mathrm{wt} \%$ \\
Sulfur total & $6490 \mathrm{cal} / \mathrm{g}$ \\
Heat of combustion: & \\
\hline Analyzed by the Coal Mining Research Center. \\
\hline
\end{tabular}

tube, releasing gaseous product which were sampled through a filter and analyzed by gas chromatograph. The conversion and the mole fractions of product were determined. The reaction was carried out at atmospheric pressure. Experimental conditions and the proximate and ultimate analyses of the coal used are shown in Tables $\mathbf{1}$ and $\mathbf{2}$, respectively.

\subsection{Experimental results}

Acetylene, methane, hydrogen, and carbon monoxide were detected by gas chromatograph as product gases. No tar was detected under the present conditions. Therefore, the conversion was defined by the ratio of gasified weight of the supplied coal to initial weight.

Changes in conversion were first examined, choosing a coal feed rate which ranged from 11 to $102 \mathrm{mg} / \mathrm{s}$. The conversion decreased at feed rates over $50 \mathrm{mg} / \mathrm{s}$ because the plasma temperature decreased due to the heat capacity of the coal particles. Therefore, a coal feed rate of $47.2 \mathrm{mg} / \mathrm{s}$ was used in this study.

Figure 3 shows the effects of the argon flow rate on the conversion for two coal particle sizes and an electric input power of $3.2 \mathrm{~kW}$. The conversion increases with argon flow rate and is inversely proportional to the square of the coal particle diameter. The solid curves in this and the next figure show the calculated results, which will be described later. Figure 4 shows the effects of the electric input power on the conversion at an argon flow rate of $277 \mathrm{mg} / \mathrm{s}$. The conversion increases with input power under $4 \mathrm{~kW}$ because of the increase in plasma temperature, but decreases over $4 \mathrm{~kW}$. 


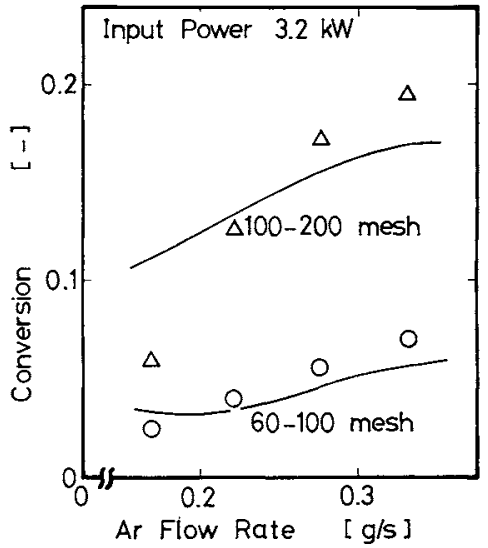

Fig. 3. Conversion vs. argon flow rate

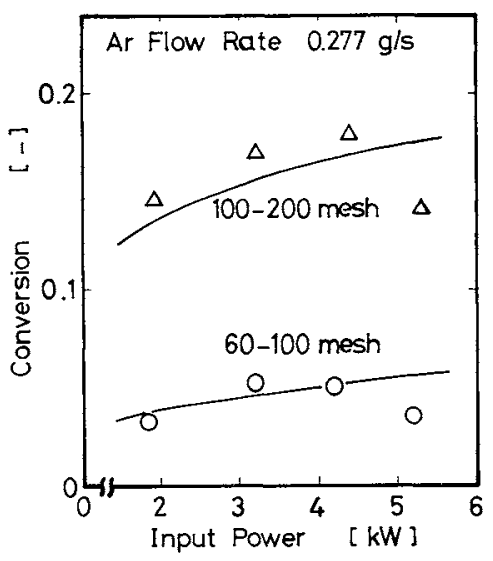

Fig. 4. Conversion vs. electric input power.

Figures 5 and $\mathbf{6}$ show the mole fraction changes of the product gases for a coal size of 60-100 mesh. They show that the mole fractions do not significantly depend on either the argon flow rate or the input power.

\section{Calculations}

The conversion can be evaluated by solving, the unsteady heat conduction problem within a coal particle. This requires information concerning the trajectory of the particle.

2.1 Trajectory of a particle in a field of non-uniform temperature and velocity in the reacting tube

As the temperature and velocity distributions of the plasma flow in the reacting tube were known to be a function of the plasma flow rate and the input power ${ }^{10)}$ the trajectory of the particle was numerically calculated by solving the following momentum equations.

$$
\begin{aligned}
& \frac{d V_{r}}{d t}=-\frac{3}{4} c_{D} \frac{\rho_{p}}{\rho_{c} D_{c}}\left\{V_{r}^{2}+\left(u-V_{z}\right)^{2}\right\}^{1 / 2} V_{r} \\
& \frac{d V_{z}}{d t}=\frac{3}{4} c_{D} \frac{\rho_{p}}{\rho_{c} D_{c}}\left\{V_{r}^{2}+\left(u-V_{z}\right)^{2}\right\}^{1 / 2}\left(u-V_{z}\right)-g
\end{aligned}
$$

The collision with the wall is assumed to be perfectly

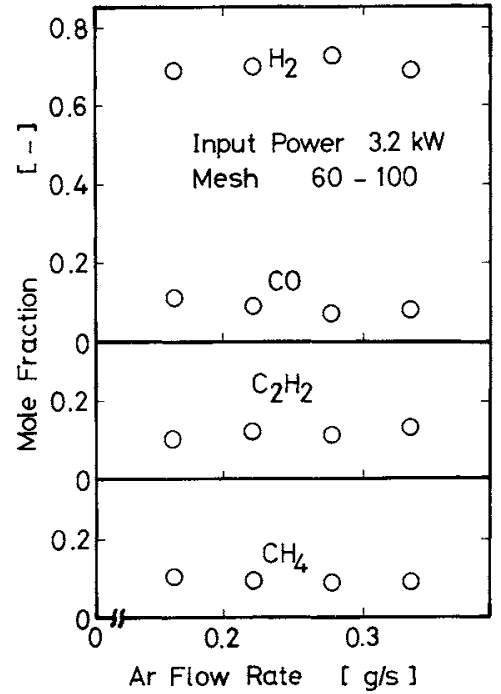

Fig. 5. Mole fractions vs. argon flow rate.

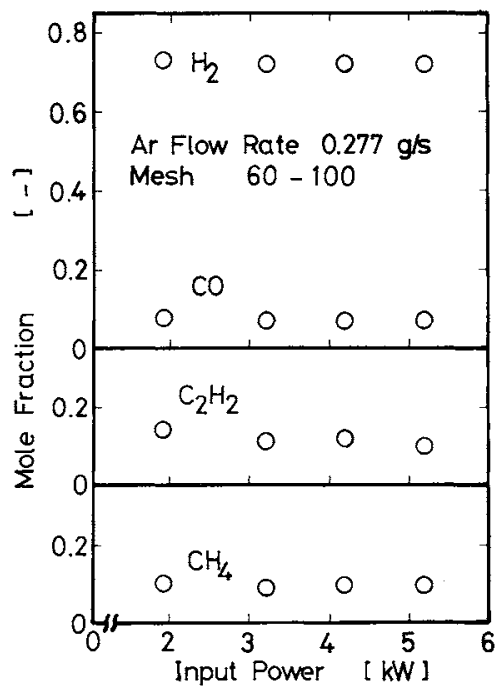

Fig. 6. Mole fractions vs. electric input power.

Table 3. Properties of "Taiheiyo" coal

\begin{tabular}{cclcl}
\hline & & & & Units \\
$T_{d}$ & $723^{17}$ & $T_{\text {sub }}$ & $3672^{13)}$ & $\mathrm{K}$ \\
$\Delta H_{d}$ & $7.41^{5,}$ & $\Delta H_{\text {sub }}$ & $59.8^{14)}$ & $\mathrm{MJ} / \mathrm{kg}$ \\
$\rho_{c}$ & $750^{7)}$ & $\rho_{d}$ & $450^{*}$ & $\mathrm{~kg} / \mathrm{m}^{3}$ \\
$c_{p c}$ & $1050^{7)}$ & $c_{p d}$ & $1050^{* *}$ & $\mathrm{~J} / \mathrm{kg} \cdot \mathrm{K}$ \\
$k_{c}$ & $0.256^{7)}$ & $k_{d}$ & $0.154^{*}$ & $\mathrm{~W} / \mathrm{m} \cdot \mathrm{K}$ \\
\hline$*$ & $750 \times 0.6=450 ; 0.256 \times 0.6=0.154$. & \\
$*$ & & \\
$*$
\end{tabular}

elastic. The drag coefficient $C_{D}$ is given in the literature, ${ }^{11)}$ and the properties of the coal are shown in Table 3. The residence time of the particles in the reacting tube was numerically estimated at about $5 \mathrm{~ms}$.

2.2 Thermal decomposition of a fine particle of coal in a field of uniform temperature and velocity

First, the amount of thermal decompostion of a 


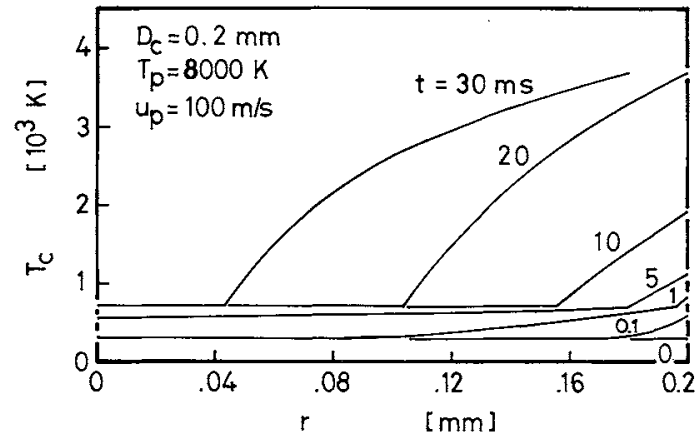

Fig. 7. Radial temperature profiles in a coal particle.

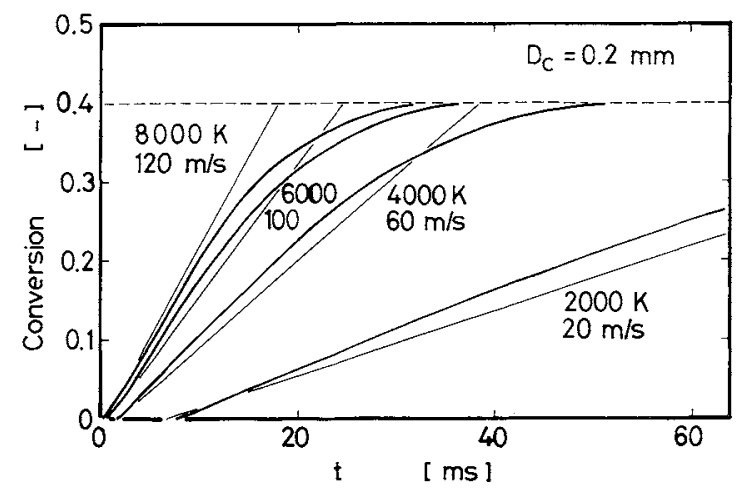

Fig. 8. Changes in conversion with time.

spherical particle of coal in a field of uniform temperature and velocity was calculated along with time by solving a one-dimensional unsteady heat conduction problem. The phase change and the evolution of gaseous products were included as the result of thermal decomposition. ${ }^{5,6,8,12,16}$ ) The assumptions used in this calculation are:

a) the decomposition rate is limited by the heat transfer from the plasma to a particle,

b) radiation is negligible,

c) only gaseous products are released from the coal particle (no tar was observed),

d) the coal particle decomposes at a constant temperature, and

e) the diameter of the coal particle does not vary during the decomposition.

The diameters of the spherical particles were 0.1 and $0.2 \mathrm{~mm}$ corresponding to the size of $100-200$ and 60-100 mesh, respectively, used in the experiment.

2.2.1 Temperature profiles in a coal particle using numerical analysis The radial profiles of temperature in a $0.2 \mathrm{~mm}$-diameter particles were calculated by numerical analysis and are shown in Fig. 7, where the parameter is the reaction time. The procedures of the numerical method are given in Appendix. The initial temperature of the particle is $300 \mathrm{~K}$, and the plasma temperature is $8000 \mathrm{~K}$. First, the particle is heated, and then decomposes at $0.2 \mathrm{~ms}$. At time $30 \mathrm{~ms}$, the surface of the particle begins to sublimate and the

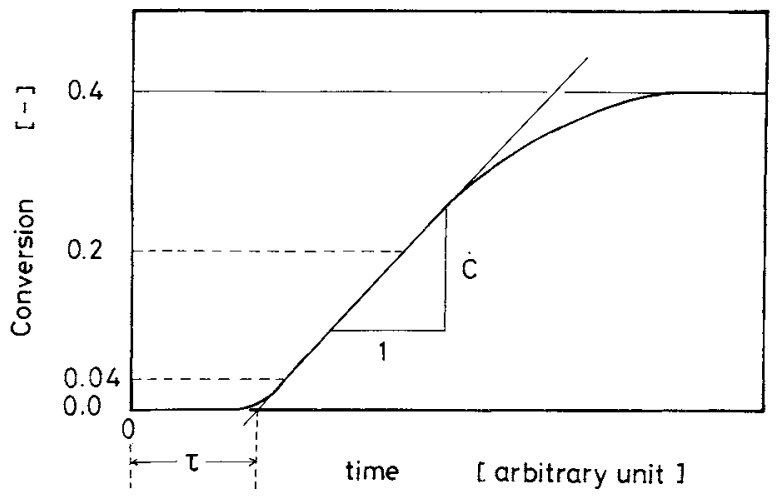

Fig. 9. Definition of $\tau$ and $c^{\prime}$.

radius is decreasing to $0.18 \mathrm{~mm}$ from the initial value of $0.20 \mathrm{~mm}$.

The residence time of the particle in the reacting tube is about $5 \mathrm{~ms}$, as mentioned in section 2.1 , and the plasma temperature of $8000 \mathrm{~K}$ is considered to be the highest under these experimental conditions. Therefore, the particle does not sublimate under the present conditions. This supports assumption e. At $5 \mathrm{~ms}$, the temperature of the particle is about $1100 \mathrm{~K}$, and the amount of radiation from the surface is onehundredth at most of that of the heat transfer from the plasma. This supports assumption $b$.

The thick curves in Fig. 8 show some typical calculated results of the conversion of a $0.2 \mathrm{~mm}$ diameter particle as a function of time elapsed. The parameters in this figure are the plasma temperature and velocity. The conversion increases rapidly in regions of high temperature and velocity. However, the calculated conversions do not exceed 0.4 because only the volatile matter is assumed to decompose. The thin lines, which also show calculated results, are mentioned in the next section.

2.2.2 Evaluations of heating time and conversion rate using energy balance From the above results shown by thick curves, the following two periods may be considered:

1) the heating period $\tau_{j}$ in which the particle is heated up to the decomposition temperature and does not decompose, and

2) the decomposition period in which the particle decomposes and the conversion increases linearly up to 0.4 (the conversion rate is given from the slope as a constant $c_{j}^{\prime}$ ).

The heating time $\tau_{j}$ and the conversion rate $c_{j}^{\prime}$ are defined as shown in Fig. 9, and the two are obtained from the energy balance between a coal particle and the plasma as follows.

The energy balance during the heating period is

$$
\frac{1}{6} D_{c}^{3} \rho_{c} c_{p c}\left(T_{d}-T_{i}\right)=D_{c}^{2} h^{0}\left(T_{p}-T_{\mathrm{s}}\right) \tau_{j}
$$

where 1) the temperature in the coal particle is 
assumed uniform, and 2) the surface temperature $T_{s}$ is also assumed to be given as the arithmetic mean of $T_{i}$ and $T_{d}$. And, $h^{0}$ is given by Eq. (A-8). $\tau_{j}$ is obtained from this equation as a function of $T_{p}$ and velocity.

The energy balance during the decomposition period is

$$
\begin{array}{r}
\frac{1}{6} D_{c}^{3} \rho_{c} c_{j}^{\prime}\left\{\Delta H_{d}+c_{p d}\left(T_{s}-T_{d}\right)\right\} \\
=D_{c}^{2} h^{0} \frac{B}{\exp (B)-1}\left(T_{p}-T_{s}\right)
\end{array}
$$

The heat flux at the surface is given by

$$
k_{d} \frac{T_{s}-T_{d}}{D_{c} / 2}=h^{0} \frac{B}{\exp (B)-1}\left(T_{p}-T_{s}\right)
$$

$c_{j}^{\prime}$ and $T_{s}$ are calculated from Eqs. (4) and (5). These evaluations require iteration of the calculation because the blowing parameter $B$ is a function of $c_{j}^{\prime}$.

The values of $\tau_{j}$ and $c_{j}^{\prime}$ are shown by the thin solid lines in Fig. 8 for $D=0.2 \mathrm{~mm}$. The required time for decomposition is one fourth that for $D=0.1 \mathrm{~mm}$. No changes in particle temperature can be observed experimentally, so that the results obtained by the energy balance method are comparable with those by numerical analysis. As the thin lines agree with the results of numerical analysis as shown by the thick curves in Fig. 8, the energy balance method is of similar quality for estimation of the conversion as is numerical analysis. The energy balance method was used in evaluation of the conversion afterwards.

\subsection{Calculation of conversion using heating time and conversion rate}

$\tau$ and $c^{\prime}$ are estimated from the results of $\tau_{j}$ and $c_{j}^{\prime}$ obtained by the energy balance method under the corresponding temperature and velocity conditions obtained from the calculation of the trajectory of a particle.

The total amount of heat from the plasma flow to a coal particle in the heating period $Q$ is given by

$$
\frac{Q}{M_{c} c_{p c}}=\int \frac{d T}{d t} d t=\sum_{j=1}^{1} \frac{T_{d}-T_{j}}{\tau_{j}} \Delta t
$$

where $\Delta t$ is a time increment and $\tau_{j}$ is the heating time corresponding to the temperature and velocity conditions at the $j$-th time segment. As the amount of heat required to heat up the particle to the decomposition temperature is given by $M_{c} c_{p c}\left(T_{d}-T_{i}\right)$, the following equation is obtained.

$$
\sum_{j=1}^{m} \frac{\Delta t}{\tau_{j}}=1
$$

where $m$ is determined so as to satisfy Eq. (7) and denotes the time of the end of the heating period. The heating time $\tau$ is obtained'as $m \Delta t$.

In the decomposition period, the conversion at time $n \Delta t$ is obtained by the following equation.

$$
\sum_{j=m+1}^{n} c_{j}^{\prime} \Delta t=c
$$

where $c_{j}^{\prime}$ is the conversion rate at time $j \Delta t$ obtained by the energy balance method for a uniform field that has the same temperature and velocity as the actual field in the reaction tube. The effects of the injection velocity of the particle on the conversion were numerically examined, and are not significant except for the very low-velocity region. The error caused by the injection velocity is considered to be small in this experiment.

\subsection{Comparison with the experimental values}

The results of the energy balance method are shown as solid curves in Figs. 3 and 4 . These results are in good agreement with the experimental values. Therefore, the assumptions of this calculation are considered to be reasonable. Figure 3 shows that conversion increases with plasma flow rate. This can be explained by the fact that a high plasma flow rate causes a high temperature of the plasma flow. The calculated conversions, solid curves in Fig. 4, monotonically increase with input power. However, the experimental results have maxima. The decrease in the conversion observed experimentally over $4 \mathrm{~kW}$ can be considered to be caused by the fusion of the particle surface, which prevents product gas release from the coal.

\section{Conclusions}

Hydrogen, methane, acetylene, and carbon monoxide were observed as product gases of thermal decomposition of "Taiheiyo" coal, using a thermal argon plasma. The experimentally observed conversion increases with the argon plasma flow rate and has a maximum against the input power. Experimentally observed changes in mole fractions were not significantly large.

The variations in conversion with argon flow rate and input power were calculated and agreed with the experimental results within the experimental error limits, using a combination of the energy balance method and the results of the trajectory calculation of a coal particle. The heat transfer limiting step and a constant decomposition temperature are assumed in the calculation.

\section{Appendix}

The temperature distribution in a coal particle is obtained by solving a one-dimensional unsteady heat conduction equation:

$$
\rho_{c} c_{p c} \frac{\partial T}{\partial t}=\frac{1}{r^{2}} \frac{\partial}{\partial r}\left(r^{2} k_{c} \frac{\partial T}{\partial r}\right)
$$

where the initial condition is

$$
T=T_{i} \quad \text { at } \quad t=0
$$


and the boundary conditions are as follows.

$$
\begin{array}{ll}
\frac{\partial T}{\partial r}=0 & \text { at } r=0 \\
h\left(T_{p}-T\right)=k_{c} \frac{\partial T}{\partial r} & \text { at } r=R
\end{array}
$$

When the temperature reaches the decomposition temperature, the following boundary condition is added.

$$
T=T_{d} \quad \text { at } \quad r=r^{\prime}
$$

where $r^{\prime}$ is the radial position of the reacting spherical interface. Furthermore, when the surface temperature of the particle reaches the sublimation temperature of carbon, one more boundary condition,

$$
T=T_{\text {sub }} \quad \text { at } \quad r=R
$$

is added and the sublimation is taken into consideration.

The heat transfer coefficient is obtained as follows.

$$
h=h^{0}-\frac{B}{\exp (B)-1}
$$

where

$$
h^{0}=\frac{k_{p}}{D_{c}} N u=\frac{k_{p}}{D_{c}}\left(2+0.6 R e^{1 / 2} \operatorname{Pr}^{1 / 3}\right)
$$

$B$ in Eq. (A-7) is a blowing parameter showing the gas blowing effect on $h$ and is given by

$$
B=\frac{\rho_{w} u_{w} c_{p w}}{h^{0}}=\frac{D_{c}}{6} c^{\prime} \frac{c_{p w}}{h^{0}}
$$

where $\rho_{w} u_{w}$ is estimated from the experimental decomposition rate $c^{\prime}$ as shown on the right-hand side of Eq. (A-9).

Equation (A-1) is converted to a finite difference equation and solved by the explicit method, since Eq. (A-1) is parabolic.

\section{Nomenclature}

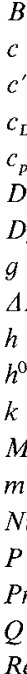

$B$
$c^{\prime}$
$c_{D}$
$c_{p}$
$D$
$D_{c}$
$g$
$\Delta H$
$h$
$h^{0}$
$k$
$M^{\prime}$
$m^{\prime}$
$N u$
$P$
$P r$
$Q$
$R e$

\section{$=$ blowing parameter}

$$
=\text { conversion }
$$

$=$ conversion rate

$=$ drag coefficient

$=$ specific heat

$=$ diameter of cooling tube

$=$ diameter of coal particle

$=$ gravitational acceleration

$=$ enthalpy change

$=$ heat transfer coefficient

$=h$ without blowing

$=$ thermal conductivity

$=$ mass

$=$ mass flow rate of argon

$=$ Nusselt number

$=$ partial pressure

$=$ Prandtl number

= accumulated amount of heat to a particle

$=$ Reynolds number
$=$ radial coordinate

[m]

$=$ radius of reacting interface

$=$ temperature

$=$ time

$=$ time increment

$=$ plasma flow velocity

$=$ particle velocity

$=$ axial coordinate

= heating time
$=$ mass density

〈Subscripts〉

$$
\begin{array}{ll}
c & =\text { coal } \\
d & =\text { decomposition, or decomposed part of coal } \\
i & =\text { initial } \\
j & =j \text {-th time segment, or uniform field } \\
p & =\text { plasma } \\
r & =\text { radial coordinate } \\
s & =\text { surface } \\
\text { sub } & =\text { sublimation } \\
w & =\text { wall } \\
z & =\text { axial coordinate }
\end{array}
$$

\section{Literature Cited}

1) Baba, A., A. Terui and H. Honda: "Sekitan Kagaku Kougyou," p. 97, Sangyo Tosho (1960).

2) Bond, R. L., I. F. Galbraith, W. R. Ladner and G. I. T. McConnell: Nature, 200, 1313 (1963).

3) Bond, R. L., W. R. Ladner and G. I. T. McConnell: Fuel, 45, 381 (1966).

4) Chakravartty, S. C., D. Dutta and A. Lahiri: Fuel, 55, 43 (1976).

5) Davies, W. B. von and D. J. Brown: Brennstoff-Chemie, 50, 163 (1969).

6) Fiszdon, J. K.: Int. J. Heat Mass Trans, 22, 749 (1979).

7) Funasaka, W. and C. Yokokawa: "Sekitan Kagaku," p. 54, Kyouritsu Shuppan (1960).

8) Garratt, M. J. and K. Littlewood: Proc. 4th Int. Symp. on Plasma Chem., p. 408 (1979).

9) Graves, R. D., W. Kawa and R. W. Hiteshue: I \& EC Process Design and Devel., 5, 59 (1966).

10) Kobayashi, M., T. Honda and A. Kanzawa: Plasma Chem. Plasma Processing, 4, 43 (1984).

11) Marchildon, E. K. and W. H. Gauvin: AIChE J., 25, 938 (1979).

12) Munz, R. J. and W. H. Gauvin: AIChE J., 21, 1132 (1975).

$\left[\mathrm{W} / \mathrm{m}^{2} \cdot \mathrm{K}\right]$

$\left[\mathrm{W} / \mathrm{m}^{2} \cdot \mathrm{K}\right]$

$[\mathrm{W} / \mathrm{m} \cdot \mathrm{K}]$

13) Nippon Kagaku-Kai (ed.): "Kagaku Binran: Kiso-Hen I," p. 42, Maruzen (1966).

14) Nippon Kagaku-Kai (ed.): "Kagaku Binran: Kiso-Hen II," p. 777, Maruzen (1966).

15) Rau, E. and L. Seglin: Fuel, 43, 147 (1964).

16) Sayegh, N. N. and W. H. Gauvin: AIChE J., 25, 1057 (1979).

17) Sheer, C., S. Korman and T. J. Dougherty: Proc. 4th Int. Sym. on Plasma Chem., p. 277 (1979). 